\title{
Changes in Serum Levels of Type-III Interferons in Ankylosing Spondylitis Treated With Tumor Necrosis Factor-Alpha Inhibitors
}

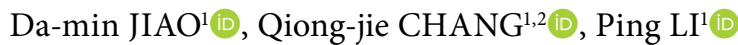 \\ ${ }^{1}$ Department of Rheumatology and Immunology, China-Japan Union Hospital of Jilin University, Changchun, China \\ ${ }^{2}$ Department of Rheumatology and Immunology, People's Hospital of Zhengzhou, Zhengzhou, China
}

\begin{abstract}
Objectives: This study aims to determine the changes in serum levels of type-III interferons (type-III IFNs) in ankylosing spondylitis (AS) patients treated with tumor necrosis factor-alpha inhibitors (TNFi) and analyze the correlations between serum type-III IFN levels and disease activity.

Patients and methods: The study included 57 AS patients (51 males, 6 females; mean age $29.7 \pm 7.0$ years; range, 18 to 50 years), who had been diagnosed with AS and had active disease before the start of the study (median disease duration: four years, range 1.3 to 8.0 years). Control group included 50 healthy, age- and sex-matched individuals (45 males, 5 females; mean age $25.5 \pm 6.7$ years; range, 18 to 55 years). The enzyme-linked immunosorbent assay was used to assess the serum interleukin (IL)-29, IL-28A, and IL-28B levels of AS patients at baseline and first, third, sixth months after treatment with TNFi. Clinical and laboratory features of the disease were also evaluated for AS patients at baseline and first, third, sixth months after treatment.

Results: Serum IL-28A levels were significantly higher in AS patients $(354.8 \pm 164.0 \mathrm{pg} / \mathrm{mL})$ than in controls $(257.2 \pm 99.6, \mathrm{p}=0.003)$ at baseline. Serum IL-28B levels were significantly lower in AS patients (median, $491.4 \mathrm{pg} / \mathrm{mL}$, range 296.6 to $944.6 \mathrm{pg} / \mathrm{mL}$ ) than in controls $(1121.1 \pm 409.3 \mathrm{pg} / \mathrm{mL}$, $\mathrm{p}=0.000$ ) at baseline. Serum IL-29 levels at third month after treatment (median 430.9, range 277.4 to $1023.9 \mathrm{pg} / \mathrm{mL}$ ) were significantly increased compared with baseline (median 399.1, range 261.2 to $826.7 \mathrm{pg} / \mathrm{mL}$ ), $\mathrm{p}=0.002$ ) and controls $(335.2 \pm 100.5 \mathrm{pg} / \mathrm{mL}, \mathrm{p}=0.041)$. There was no association between serum type-III IFN levels and disease activity indexes at baseline. Serum levels of IL-28A were negatively correlated with erythrocyte sedimentation rate levels at first and sixth months after treatment ( $r=-0.266, p=0.046 ; r=-0.286, p=0.034$, respectively). Serum levels of IL-28A were negatively correlated with Bath Ankylosing Spondylitis Disease Activity Index at third month after treatment ( $r=-0.269$, $p=0.043)$. Serum levels of IL-29 were negatively correlated with Bath Ankylosing Spondylitis Disease Activity Index at third month after treatment ( $r=-0.299, \mathrm{p}=0.024)$. There was a significant increasing trend for serum IL-28B after TNFi treatment in AS patients, opposite to the decreasing trend for disease activity.

Conclusion: These findings indicate that type-III IFNs may be involved in the pathogenesis of AS. Thus, type-III IFNs may provide new targets for the treatment of AS.

Keywords: Ankylosing spondylitis; autoimmune disease; interferons; treatment.
\end{abstract}

Ankylosing spondylitis (AS) is a kind of progressive arthritis caused by long-term chronic inflammatory stimuli in the joints of the spine. Tumor necrosis factor-alpha (TNF- $\alpha$ ) is widely accepted as the most important inflammatory cytokine in AS development. Convincing data from clinical trials have demonstrated dramatic benefits of tumor necrosis factor inhibitor (TNFi) in AS patients, which include reducing disease severity. ${ }^{1,2}$
Type-III interferons (type-III IFNs) are newly described members of the IFN family and consist of three IFN- $\lambda$ s molecules called interleukin (IL)-29 (IFN- $\lambda 1$ ), IL-28A (IFN- $\lambda 2$ ), and IL-28B (IFN- $\lambda 3$ ). A variant upstream of the IFN- $\lambda 3$ gene was recently described and named IFN- $\lambda 4$ gene. ${ }^{3}$ These IFN- $\lambda \mathrm{s}$ signals induce activation of the Janus kinase-signal transducer and activator of transcript, mitogen-activated protein kinase or

Received: October 16, 2017 Accepted: February 14, 2018 Published online: May 17, 2018

Correspondence: Ping Li, MD. Department of Rheumatology and Immunology, China-Japan Union Hospital of Jilin University, No.126 Xiantai Street, 130033 Changchun, China. Tel: +86-431-84995841 e-mail: lipingzt@163.com 
Akt signaling pathway through IL-28 rheumatoid arthritis (RA) and IL-10R2 receptor complexes, and exert antiviral, anti-proliferative and immunomodulatory effects. ${ }^{4-6}$ Recently, type-III IFNs have gained much interest in rheumatology with publications focusing on systemic lupus erythematosus (SLE), systemic sclerosis (SSc) and RA. ${ }^{7-9}$ Many animal models of autoimmunity and clinical researches showed that IL-28A and IL-28B exert the protective effect by inhibiting inflammatory cytokines production including IL-1 $\beta$, IL-17, TNF- $\alpha$ and neutrophil migration. ${ }^{10,11}$ IL-29 can upregulate the levels of IL-6, IL-8 and IL-10 secreted by monocytes ${ }^{12}$ and also enhance the IL-2-dependent proliferation of CD4+CD25+Foxp3+ T cells induced by dendritic cells, ${ }^{13}$ which indicate that IL-29 may play a crucial role in modulating immune response. Previous studies have shown that serum IL-29 levels are not different between AS patients and healthy controls (HCs), ${ }^{7}$ while, to our knowledge, levels of IL-28 isoforms expression and the relationship between serum type-III IFNs and disease activity in AS patients have never been reported.

Therefore, in this study, we aimed to determine the changes in serum levels of type-III IFNs in AS patients treated with TNF- $\alpha$ inhibitors and analyze the correlations between serum type-III IFN levels and disease activity.

\section{PATIENTS AND METHODS}

In this retrospective study, a total of 57 patients (51 males, 6 females; mean age 29.7 \pm 7.0 years; range, 18 to 50 years) were recruited, who were diagnosed with AS and hospitalized between September 2015 and September 2017 at the Department of Rheumatology and Immunology of China-Japan Union Hospital of Jilin University in China. All patients met the 1984 modified New York criteria for AS. ${ }^{14}$ Also, 50 age- and sex-matched HCs (45 males, 5 females; mean age $25.5 \pm 6.7$ years; range, 18 to 55 years) were included. Individuals in the control group were recruited from the physical examination center and had no history of rheumatism, infectious disease or other systemic disease. AS patients with a Bath Ankylosing Spondylitis Disease Activity Index (BASDAI) $\geq 4^{15}$ or Ankylosing
Spondylitis Disease Activity Score (ASDAS) using C-reactive protein (CRP) [ASDAS-CRP] $\geq 2.1^{16}$ were defined as active and were assessed at baseline and first, third, sixth months after treatment. These patients received TNFi treatment (TNF- $\alpha$ fusion protein, etanercept) for $25 \mathrm{mg}$ twice weekly together with one of non-steroidal anti-inflammatory drugs including celecoxib, diclofenac, and etoricoxib. Major exclusion criteria were infections, diabetes, heart failure, renal failure, hepatitis, hepatic failure or malignant diseases and other active inflammatory diseases (e. g., RA, Crohn's disease, SLE, SSc). Patients who were receiving drugs with direct influence on immune system (e.g., disease-modifying antirheumatic drugs [DMARDs], glucocorticoids) were excluded. The parameters, including age, sex, disease duration, CRP, erythrocyte sedimentation rate (ESR), BASDAI score, Bath Ankylosing Spondylitis Functional Index (BASFI) score, ${ }^{17}$ Bath Ankylosing Spondylitis Metrology Index (BASMI), ${ }^{18}$ and ASDAS-CRP were assessed through questionnaires and reviews of medical records. BASMI, BASFI and BASDAI were used to assess spinal mobility, functional status and disease activity, respectively. All scores ranging from 0 to 10 were averaged, with higher scores indicating greater severity. CRP levels (mg/L) were measured using immunoturbidimetry method (CRP Turbilatex, Reliable Medical Supply \& Co, MN, USA). CRP was measured in fresh samples in order to determine ASDAS-CRP score. The Westergren method was utilized to detect ESR levels ( $\mathrm{mm} /$ hour). The study protocol was approved by the China-Japan Union Hospital of Jilin University Ethics Committee. A written informed consent was obtained from each participant. The study was conducted in accordance with the principles of the Declaration of Helsinki.

Disease activity was measured with the AS disease activity score, including ASDAS-CRP and BASDAI. The Assessments in Ankylosing Spondylitis (ASAS) 20 response criteria ${ }^{19}$ were used to define treatment response. Patients who fulfilled ASAS20 response criteria after TNFi therapy in the first three months were classified as the response positive group. Patients who did not fulfill ASAS20 response criteria after TNFi therapy in the first three months were classified as the no response group. 
Fasting blood was collected in tube containing clot activator (BD Vacutainer, 367983, Becton, Dickinson and Co., Franklin Lakes, NJ, USA) and tube with Na-citrate 3.2\% (BD Seditainer, 366676, Becton, Dickinson and Co., Franklin Lakes, NJ, USA) at baseline and first, third, sixth months after treatment. All samples were collected prior to the next TNFi injection. Tubes were centrifuged at 3,600 revolutions per minute for eight minutes at $4^{\circ} \mathrm{C}$. After centrifugation, serum was aliquoted and stored at $-80^{\circ} \mathrm{C}$ until determination of IL-29, IL-28A, and IL-28B.

The serum levels of IL-29, IL-28A, and IL-28B were measured by human enzyme-linked immunosorbent assay (ELISA) kit according to the manufacturer's instructions: IL-29 (BMS2049, eBioscience, San Diego, USA), IL-28A (GWBSKR146, GenWay Biotech, San Diego, USA), and IL-28B (GWB-SKR147, GenWay Biotech, San Diego, USA). Point optical densities at $450 \mathrm{~nm}$ were determined using a VERSAmax spectrophotometer (Molecular Devices, Sunnyvale, CA, USA) to draw the standard curves and the concentrations of the indicated cytokines were calculated according to the corresponding standard curves using SoftMax software (Molecular Devices, Sunnyvale, California, USA).

\section{Statistical analysis}

The normal distribution data were expressed as the mean \pm standard deviation, and the nonnormal distribution data were expressed as the median (interquartile range). After checking normal distribution with the Kolmogorov-Smirnov test, independent t-test and Mann-Whitney U test were used to compare the parameters between the AS patients and HCs. Paired t-tests and Wilcoxon signed rank tests were used to compare the parameters between measuring points of zero-, one-, three-, and six-month values where appropriate. The relationship between variables was evaluated using the Spearman rank correlation test for non-normal distributions and Pearson's correlation test for normal distributions. Statistical analyses were performed with IBM SPSS version 23.0 (IBM Corp., Armonk, NY, USA). The GraphPad Prism 7.0 software (GraphPad Software, La, Jolla, CA, USA) was used for figure production. Two-tailed $p$ values less than 0.05 were considered to be statistically significant.

Table 1. Baseline characteristics of ankylosing spondylitis patients and healthy controls

\begin{tabular}{|c|c|c|c|c|c|c|c|c|}
\hline \multirow[t]{2}{*}{ Parameter } & \multicolumn{4}{|c|}{ AS patients $(n=57)$} & \multicolumn{4}{|c|}{ Healthy controls $(n=50)$} \\
\hline & $\mathrm{n}$ & Mean \pm SD & Median & $\begin{array}{c}\text { Interquartile } \\
\text { ranges }\end{array}$ & $\mathrm{n}$ & Mean \pm SD & Median & $\begin{array}{c}\text { Interquartile } \\
\text { ranges }\end{array}$ \\
\hline Age (year) & & $29.7 \pm 7.0$ & 28.0 & $24.0-34.0$ & & $25.5 \pm 6.7$ & - & - \\
\hline $\begin{array}{l}\text { Sex } \\
\text { Female } \\
\text { Male }\end{array}$ & $\begin{array}{c}6 \\
51\end{array}$ & & & & $\begin{array}{c}5 \\
45\end{array}$ & & & \\
\hline Disease duration (year) & & & 4 & $1.3-8.0$ & & & - & - \\
\hline BASDAI & & & 5.4 & $4.9-6.6$ & & & - & - \\
\hline BASFI & & $4.5 \pm 2.4$ & & & & - & & \\
\hline BASMI & & & 3.0 & $1.0-4.0$ & & & - & - \\
\hline ASDAS-CRP & & $3.8 \pm 0.8$ & & & & - & & \\
\hline $\mathrm{CRP}(\mathrm{mg} / \mathrm{L})$ & & & 15.9 & $8.7-52.2$ & & & - & - \\
\hline ESR (mm/hour) & & & 18.0 & $10.5-47.0$ & & & - & - \\
\hline IL-29 (pg/mL) & & & 399.1 & $261.2-826.7$ & & $335.2 \pm 100.5$ & - & - \\
\hline IL-28A (pg/mL) & & $354.8 \pm 164.0^{*}$ & & & & $257.2 \pm 99.6$ & & \\
\hline IL-28B (pg/mL) & & & 491.4 & 296.6-944.6* & & $1121.1 \pm 409.3$ & - & - \\
\hline
\end{tabular}




\section{RESULTS}

The baseline characteristics of the AS patients and HCs were shown in Table 1. Our results revealed that the serum IL-28A levels were significantly higher in AS patients than those in HCs $(p=0.003)$, while the serum IL-28B levels were significantly lower in AS patients than those in HCs $(p=0.000)$. There was no significant
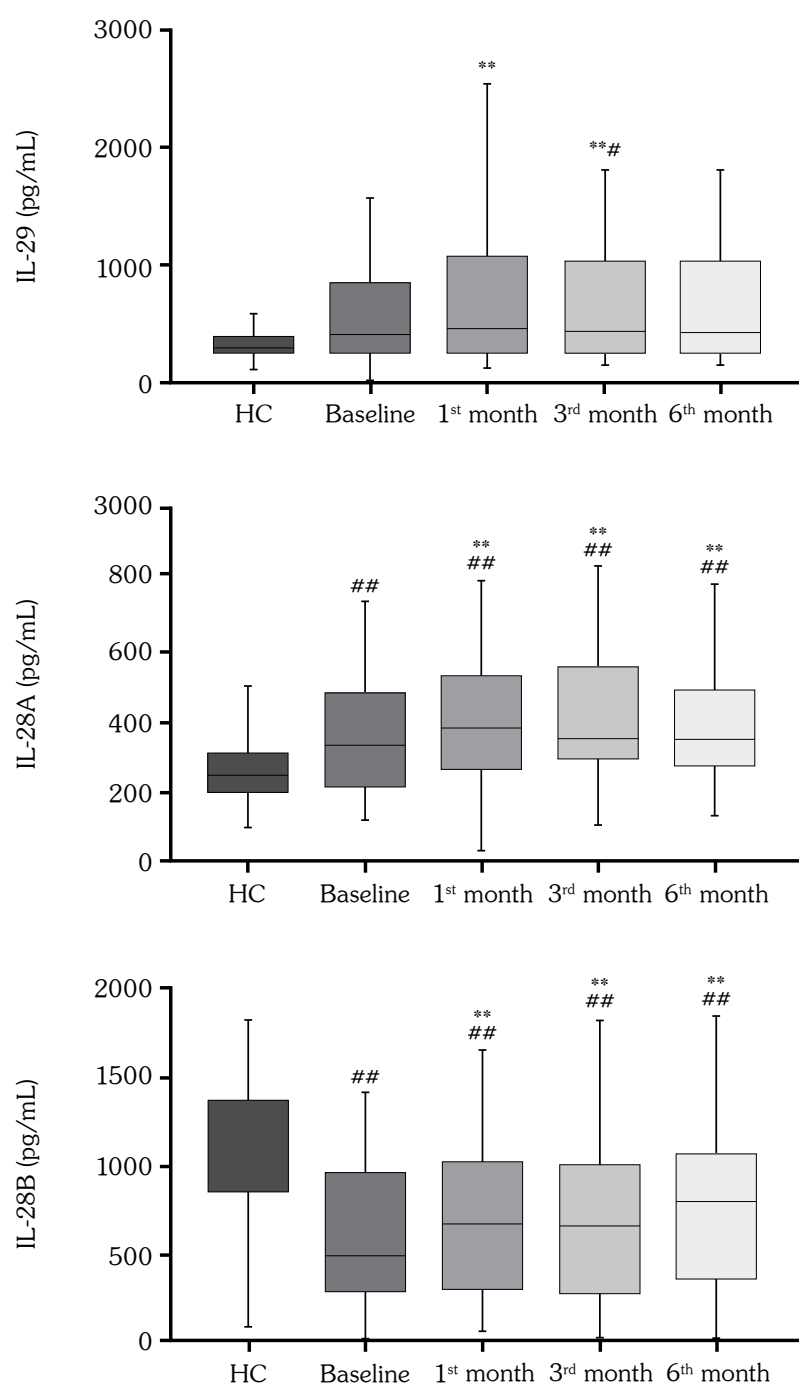

Figure 1. Follow-up data of serum interleukin-29, interleukin-28A and interleukin-28B levels in ankylosing spondylitis patients before and after treatment with tumor necrosis factor inhibitor were compared with healthy controls; Data are presented as box-and-whisker plots where central box represents values from lower to upper quartile (27 to 75 percentile). Middle line represents median. A line extends from minimum to maximum value. Significance levels were shown as $\# p<0.05$ and $\# \# p<0.01$ when comparing ankylosing spondylitis patients and healthy controls; ${ }^{* *} \mathrm{p}<0.01$ when comparing ankylosing spondylitis patients before and after treatment; HC: Healthy controls; IL: Interleukin. difference in serum IL-29 levels between AS patients and HCs.

As shown in Figure 1, serum IL-28A levels in AS patients at baseline and first, third, sixth months after TNFi treatment were significantly higher than those in HCs $(p<0.01)$. Serum IL-28B levels in AS patients at baseline and first, third, sixth months after TNFi treatment were significantly lower than those in HCs $(p<0.01)$. Serum IL-29 levels in AS patients only at third months after TNFi treatment were significantly higher than those in HCs $(p<0.05)$.

The changes in serum levels of IL-29, IL-28A, and IL-28B in AS patients according to further comparison of the parameters obtained after first, third, sixth months of TNFi treatment were shown in Table 2 and Figure 2. Serum levels of IL-28A at first, third, sixth months were significantly different from baseline $(p<0.01)$. According to Figure 2, IL-28A might have a rising tendency after first month treatment, but have a declining tendency from the third month after treatment to close to the normal expression levels. Serum IL-28B levels were significantly higher at first, third, sixth months after TNFi treatment compared with baseline $(p<0.01)$. There was a tendency for serum IL-28B levels to continue to rise and approach normal values. Serum IL-29 levels were significantly higher at first, third, months after TNFi treatment compared with baseline $(p<0.01)$. There was no statistical difference in IL-29, IL-28A or IL-28B between measuring points of first, third, sixth months ( $p>0.05)$.

We investigated the disease activity indexes at different time points (Table 2) and found a significant decrease in disease activity indexes at first, third, sixth months after TNFi treatment compared with baseline, including ESR, CRP, BASDAI, and ASDAS-CRP $(p<0.01)$. We demonstrated that serum levels of IL-29, IL-28A, IL-28B, ESR, and CRP were in a steady-state level first month after treatment till the sixth month $(p<0.05)$; ASDAS-CRP score continued to decline till third months after treatment, and then remained in a steadystate; BASDAI continued to decline during the treatment period.

We compared the correlation of IL-29, IL-28A, and IL-28B with disease activity indexes ESR, 

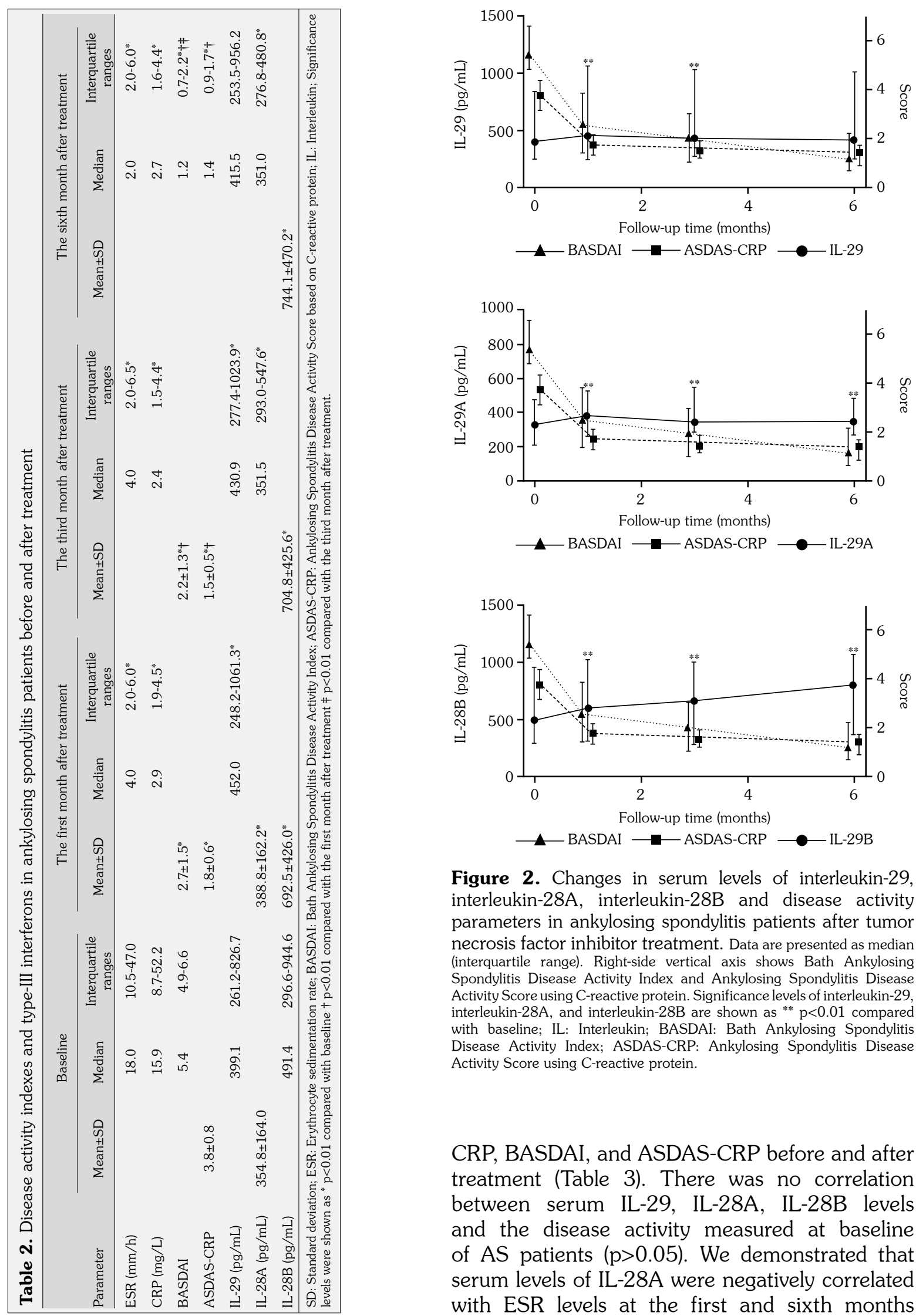

Figure 2. Changes in serum levels of interleukin-29, interleukin-28A, interleukin-28B and disease activity parameters in ankylosing spondylitis patients after tumor necrosis factor inhibitor treatment. Data are presented as median (interquartile range). Right-side vertical axis shows Bath Ankylosing Spondylitis Disease Activity Index and Ankylosing Spondylitis Disease Activity Score using C-reactive protein. Significance levels of interleukin-29, interleukin-28A, and interleukin-28B are shown as ${ }^{* *} \mathrm{p}<0.01$ compared with baseline; IL: Interleukin; BASDAI: Bath Ankylosing Spondylitis Disease Activity Index; ASDAS-CRP: Ankylosing Spondylitis Disease Activity Score using C-reactive protein.

CRP, BASDAI, and ASDAS-CRP before and after treatment (Table 3). There was no correlation between serum IL-29, IL-28A, IL-28B levels and the disease activity measured at baseline of AS patients ( $p>0.05)$. We demonstrated that serum levels of IL-28A were negatively correlated with ESR levels at the first and sixth months 


\begin{tabular}{|c|c|c|c|c|c|}
\hline & & $\mathrm{ESR}(\mathrm{mm} / \mathrm{h})$ & $\mathrm{CRP}(\mathrm{mg} / \mathrm{L})$ & BASDAI & ASDAS-CRP \\
\hline \multicolumn{6}{|l|}{ Baseline } \\
\hline \multirow[t]{2}{*}{ IL-29 } & $\mathrm{r}$ & 0.056 & -0.016 & 0.059 & 0.104 \\
\hline & $\mathrm{p}$ & 0.677 & 0.906 & 0.664 & 0.442 \\
\hline \multirow[t]{2}{*}{ IL-28A } & $\mathrm{r}$ & -0.179 & -0.132 & 0.037 & -0.012 \\
\hline & $\mathrm{p}$ & 0.184 & 0.329 & 0.783 & 0.928 \\
\hline \multirow{2}{*}{ IL-28B } & $\mathrm{r}$ & -0.024 & 0.063 & -0.126 & 0.010 \\
\hline & $\mathrm{p}$ & 0.858 & 0.640 & 0.349 & 0.941 \\
\hline \multicolumn{6}{|c|}{ The first month } \\
\hline \multirow[t]{2}{*}{ IL-29 } & $\mathrm{r}$ & 0.019 & -0.066 & -0.096 & -0.124 \\
\hline & $\mathrm{p}$ & 0.889 & 0.628 & 0.479 & 0.360 \\
\hline \multirow[t]{2}{*}{ IL-28A } & $\mathrm{r}$ & -0.266 & -0.132 & -0.178 & -0.257 \\
\hline & $\mathrm{p}$ & 0.046 & 0.327 & 0.184 & 0.053 \\
\hline \multirow[t]{2}{*}{ IL-28B } & $\mathrm{r}$ & 0.040 & -0.006 & -0.114 & -0.156 \\
\hline & $\mathrm{p}$ & 0.769 & 0.965 & 0.399 & 0.248 \\
\hline \multicolumn{6}{|l|}{$\begin{array}{l}\text { The third } \\
\text { month }\end{array}$} \\
\hline \multirow[t]{2}{*}{ IL-29 } & $\mathrm{r}$ & -0.070 & 0.042 & -0.299 & -0.132 \\
\hline & $\mathrm{p}$ & 0.607 & 0.756 & 0.024 & 0.326 \\
\hline \multirow[t]{2}{*}{ IL-28A } & $\mathrm{r}$ & -0.189 & -0.107 & -0.269 & -0.21 \\
\hline & $\mathrm{p}$ & 0.159 & 0.428 & 0.043 & 0.116 \\
\hline \multirow[t]{2}{*}{ IL-28B } & $\mathrm{r}$ & -0.220 & -0.030 & -0.166 & -0.211 \\
\hline & $\mathrm{p}$ & 0.101 & 0.826 & 0.218 & 0.115 \\
\hline \multicolumn{6}{|l|}{$\begin{array}{l}\text { The sixth } \\
\text { month }\end{array}$} \\
\hline \multirow[t]{2}{*}{ IL-29 } & $\mathrm{r}$ & 0.052 & 0.081 & -0.227 & 0.007 \\
\hline & $\mathrm{p}$ & 0.705 & 0.557 & 0.096 & 0.960 \\
\hline \multirow[t]{2}{*}{ IL-28A } & $\mathrm{r}$ & -0.286 & -0.042 & -0.208 & -0.089 \\
\hline & $\mathrm{p}$ & 0.034 & 0.762 & 0.127 & 0.518 \\
\hline \multirow[t]{2}{*}{ IL-28B } & $\mathrm{r}$ & 0.161 & -0.020 & -0.179 & -0.158 \\
\hline & $\mathrm{p}$ & 0.240 & 0.884 & 0.191 & 0.248 \\
\hline
\end{tabular}

after treatment $(\mathrm{r}=-0.266, \mathrm{p}=0.046 ; \mathrm{r}=-0.286$, $\mathrm{p}=0.034$, respectively); serum levels of IL-28A were negatively correlated with BASDAI at the third months after treatment $(r=-0.269, p=0.043)$; serum levels of IL-29 were negatively correlated with BASDAI at the third months after treatment $(\mathrm{r}=-0.299, \mathrm{p}=0.024)$.

When we compared the changes in serum levels of type-III IFNs and disease activity indexes (BASAI and ASDAS-CRP) (Figure 2), the increasing trend of serum IL-28A and IL-28B after TNFi treatment in AS patients was opposite to the decreasing trend of disease activity.

Possible associations between changes in disease activity and changes in IL-29, IL-28A, and IL-28B levels were also examined. However, we did not find any significant correlation between $\Delta \mathrm{IL}-29, \Delta \mathrm{IL}-28 \mathrm{~A}$, and $\Delta \mathrm{IL}-28 \mathrm{~B}$ levels and $\Delta$ clinical parameters measured in AS patients at the first month after treatment ( $p>0.05$ ) (data not shown).

All of the 57 patients in our study were divided into two groups according to their ASAS20 
response criteria to $\mathrm{TNFi}$ therapy in the first three months. As a result, 46 patients were in the response positive group, while 11 patients were in the no response group. We compared the serum IL-29, IL-28A, and IL-28B levels at baseline between the response positive group and the no response group and detected no significant difference ( $p>0.05)$ (data not shown).

\section{DISCUSSION}

The current study found that type-III IFNs are involved in several autoimmune diseases including SLE, SSc, and RA.-9 Our previous published studies showed that IL-28B may contribute to avoiding osteoclasia in RA patients, and IL-29 may correlate with disease activity parameters in RA and decline after treatment with DMARDs. ${ }^{20,21}$ The pathogenesis of AS is similar to RA, which inflammation disrupts normal bone homeostasis leading to an imbalance of bone resorption and formation. ${ }^{22}$ However, it is unclear whether IL-28A, IL-28B, and IL-29 are involved in the pathogenesis of AS.

Our results revealed that serum IL-28B levels in AS patients were lower than those in $\mathrm{HCs}$, and serum IL-28A levels in AS patients were higher than those in HCs. To the best of our knowledge, this is the first report to investigate the serum IL-28A and IL-28B levels in AS patients. Our findings in AS patients were consistent with previous results in RA patients. Lv et al. ${ }^{20}$ found that serum IL-28B levels were significantly lower in RA group than in control group, and speculated that IL-28B may be stimulated by inflammation of joint, may move to the joint cavity to decrease the production of some inflammatory factors including IL-1 $1 \beta$, TNF- $\alpha$ and IL-17 and inhibit neutrophil migration to reduce the destruction and inflammation of joint. Furthermore, CastilloMartinez et al. ${ }^{23}$ found that IL-28A levels were higher in RA patients with active disease than HCs. Combined with our results, IL-28A and IL-28B expressions in AS patients may have different changes in inflammatory environments. These results suggested that IL-28A and IL-28B are involved in the pathogenesis of AS. Thus, we may indicate that IL-28A and IL-28B expressions are dysregulated in AS patients and may have different changes in inflammatory environments.

We tested disease activity parameters and inflammation parameters (ESR or CRP), which indirectly reflect the level of inflammation and the severity of the disease. Our findings demonstrated that, with the alleviation of the disease activity after treatment, the increasing trend of serum IL-28A and IL-28B after TNFi treatment in AS patients were opposite to the decreasing trend of disease activity, and became in a steady-state after one month of treatment. IL-28A was negatively correlated with ESR and BASDAI after treatment. However, we did not find any significant correlation at baseline between IL-28 isoforms and disease activity parameters. In addition, at the amino acid level, IL-28A and IL-28B are closely similar, having a 96\% sequence identity. ${ }^{4}$ Recent findings suggested that overexpression of IL-28 isoforms exerts anti-inflammatory and protective effects by downregulating inflammatory responses in experimental collagen induced arthritis ${ }^{10}$ and lung inflammation induced by cigarette smoke exposure in mice. ${ }^{11}$ In our study with AS patients, the increased serum IL-28A and IL-28B levels after treatment also suggest that IL-28A and IL-28B may exert their influence in reducing disease activity and anti-inflammatory protection. Although there was no statistically significant correlation between IL-28 isoform at baseline, the changes in serum IL-28A and IL-28B after TNFi treatment in AS patients have potential tendency to reduce disease activity.

We demonstrated that serum IL-29 levels in 57 AS patients were not different from those of HCs. Our results were in agreement with a previous work by $\mathrm{Wu}$ et al., ${ }^{7}$ who found that the serum IL-29 levels of 21 AS patients and $42 \mathrm{HCs}$ had no significant differences. However, Wu et al. ${ }^{7}$ did not explore disease activity indexes and clinical characteristics before and after treatment. Accordingly, we detected that the serum levels of IL-29 at the third months after treatment were significantly increased compared with those of baseline and $\mathrm{HCs}$, and this change was negatively correlated with BASDAI, while serum levels of IL-29 were in a steady-state level at first month after treatment till the sixth month. On the other hand, we did not find any mechanistic explanation to support such association. So, we 
speculated that IL-29 may be involved in the pathogenesis of AS. To our knowledge, this is the first report to investigate the serum IL-29 levels in AS patients after TNFi treatment and find that IL-29 in AS patients was negatively correlated with BASDAI at three months after TNFi treatment.

In order to further examine the role of type-III IFNs in AS, we compared the levels of serum IL-29, IL-28A and IL-28B levels at baseline between response positive group and no response group. Unfortunately, there was no significant difference between the two groups. Thus, whether type-III IFNs level can be used as a biomarker for the baseline predictors of TNFi treatment response in AS still requires prospective longitudinal observational cohort studies. ${ }^{24}$

Our study has some limitations. We were aware that the short-term follow-up, moderate sample size, strict inclusion criteria, and lack of other controls (e.g., inactive AS patients and other drug treatment group) may limit our results to find any correlation at baseline between type-III INFs and disease activity parameters. In addition, although changes in serum levels of type-III INFs in AS treated with TNF- $\alpha$ inhibitors were evaluated, there was no direct evidence that type-III IFNs were correlated to disease activity. Thus, further researches are necessary to identify the correlation between type-III IFNs and clinical parameters.

In conclusion, to our knowledge, this is the first study to investigate serum levels of type-III INFs in AS patients and show that type-III INFs may be involved in the pathogenesis of AS. This study may provide new targets for the treatment of AS. Further research is necessary to identify type-III INFs' functions, expression mechanisms and signaling pathways in AS pathogenesis.

\section{Declaration of conflicting interests}

The authors declared no conflicts of interest with respect to the authorship and/or publication of this article.

\section{Funding}

The authors received no financial support for the research and/or authorship of this article.

\section{REFERENCES}

1. Braun J, Sieper J. Ankylosing spondylitis. Lancet 2007;369:1379-90.

2. McLeod C, Bagust A, Boland A, Dagenais P, Dickson R, Dundar Y, et al. Adalimumab, etanercept and infliximab for the treatment of ankylosing spondylitis: a systematic review and economic evaluation. Health Technol Assess 2007;11:1-158.

3. Prokunina-Olsson L, Muchmore B, Tang W, Pfeiffer $\mathrm{RM}$, Park $\mathrm{H}$, Dickensheets $\mathrm{H}$, et al. A variant upstream of IFNL3 (IL28B) creating a new interferon gene IFNL4 is associated with impaired clearance of hepatitis C virus. Nat Genet 2013;45:164-71.

4. Sheppard P, Kindsvogel W, Xu W, Henderson K, Schlutsmeyer S, Whitmore TE, et al. IL-28, IL-29 and their class II cytokine receptor IL-28R. Nat Immunol 2003;4:63-8.

5. Uzé G, Monneron D. IL-28 and IL-29: newcomers to the interferon family. Biochimie 2007;89:729-34.

6. Dickensheets H, Sheikh F, Park O, Gao B, Donnelly RP. Interferon-lambda (IFN- $\lambda$ ) induces signal transduction and gene expression in human hepatocytes, but not in lymphocytes or monocytes. J Leukoc Biol 2013;93:377-85.

7. Wu Q, Yang Q, Sun H, Li M, Zhang Y, La Cava A. Serum IFN- $\lambda 1$ is abnormally elevated in rheumatoid arthritis patients. Autoimmunity 2013;46:40-3.

8. Amezcua-Guerra LM, Ferrusquía-Toriz D, CastilloMartínez D, Márquez-Velasco R, Chávez-Rueda AK, Bojalil R. Limited effectiveness for the therapeutic blockade of interferon $\alpha$ in systemic lupus erythematosus: a possible role for type III interferons. Rheumatology (Oxford) 2015;54:203-5.

9. Dantas AT, Gonçalves SM, Pereira MC, de Almeida $\mathrm{AR}$, Marques $\mathrm{CD}$, Rego MJ, et al. Interferons and systemic sclerosis: correlation between interferon gamma and interferon-lambda 1 (IL-29). Autoimmunity 2015;48:429-33.

10. Blazek K, Eames HL, Weiss M, Byrne AJ, Perocheau $\mathrm{D}$, Pease JE, et al. IFN- $\lambda$ resolves inflammation via suppression of neutrophil infiltration and IL-1 $\beta$ production. J Exp Med 2015;212:845-53.

11. Qiu C, Li Y, Zhou M, Liu J, Li M, Wu Y, et al. Hydrodynamic delivery of IL-28B (IFN- $\lambda 3$ ) gene ameliorates lung inflammation induced by cigarette smoke exposure in mice. Biochem Biophys Res Commun 2014;447:513-9.

12. Jordan WJ, Eskdale J, Boniotto M, Rodia M, Kellner $\mathrm{D}$, Gallagher G. Modulation of the human cytokine response by interferon lambda-1 (IFN-lambda1/IL-29). Genes Immun 2007;8:13-20.

13. Mennechet FJ, Uzé G. Interferon-lambda-treated dendritic cells specifically induce proliferation of FOXP3-expressing suppressor $\mathrm{T}$ cells. Blood 2006;107:4417-23.

14. van der Linden S, Valkenburg HA, Cats A. Evaluation of diagnostic criteria for ankylosing spondylitis. 
A proposal for modification of the New York criteria. Arthritis Rheum 1984;27:361-8.

15. Garrett S, Jenkinson T, Kennedy LG, Whitelock H, Gaisford P, Calin A. A new approach to defining disease status in ankylosing spondylitis: the Bath Ankylosing Spondylitis Disease Activity Index. J Rheumatol 1994;21:2286-91.

16. van der Heijde D, Lie E, Kvien TK, Sieper J, Van den Bosch F, Listing $\mathrm{J}$, et al. ASDAS, a highly discriminatory ASAS-endorsed disease activity score in patients with ankylosing spondylitis. Ann Rheum Dis 2009;68:1811-8.

17. Calin A, Garrett S, Whitelock H, Kennedy LG, O'Hea J, Mallorie P, et al. A new approach to defining functional ability in ankylosing spondylitis: the development of the Bath Ankylosing Spondylitis Functional Index. J Rheumatol 1994;21:2281-5.

18. Jenkinson TR, Mallorie PA, Whitelock HC, Kennedy LG, Garrett SL, Calin A. Defining spinal mobility in ankylosing spondylitis (AS). The Bath AS Metrology Index. J Rheumatol 1994;21:1694-8.

19. Anderson JJ, Baron G, van der Heijde D, Felson DT, Dougados M. Ankylosing spondylitis assessment group preliminary definition of shortterm improvement in ankylosing spondylitis. Arthritis Rheum 2001;44:1876-86.
20. Lv C, Chang QJ, Zhao F, Bi LQ, Li P. Association of Serum Interleukin-28B with Clinical Features, Laboratory Values and Radiographic Score in Rheumatoid Arthritis Patients. Clin Lab 2017;63:757-64

21. Chang QJ, Lv C, Zhao F, Xu TS, Li P. Elevated Serum Levels of Interleukin-29 Are Associated with Disease Activity in Rheumatoid Arthritis Patients with AntiCyclic Citrullinated Peptide Antibodies. Tohoku J Exp Med 2017;241:89-95.

22. Stavre Z, Upchurch K, Kay J, Gravallese EM. Differential Effects of Inflammation on Bone and Response to Biologics in Rheumatoid Arthritis and Spondyloarthritis. Curr Rheumatol Rep 2016;18:72.

23. Castillo-Martínez D, Juarez M, Patlán M, Páez A, Massó F, Amezcua-Guerra LM. Type-III interferons and rheumatoid arthritis: Correlation between interferon lambda 1 (interleukin 29) and antimutated citrullinated vimentin antibody levels. Autoimmunity 2017;50:82-5

24. Arends S, Brouwer E, van der Veer E, Groen H, Leijsma MK, Houtman PM, et al. Baseline predictors of response and discontinuation of tumor necrosis factor-alpha blocking therapy in ankylosing spondylitis: a prospective longitudinal observational cohort study. Arthritis Res Ther 2011;13:94. 